\title{
Growth of Vertically Aligned ZnO Nanowire Arrays Using Bilayered Metal Catalysts
}

\author{
Hua Qi, Evan R. Glaser, Josh D. Caldwell, and S. M. Prokes \\ Electronics Science and Technology Division, Naval Research Laboratory, Washington, DC 20375, USA \\ Correspondence should be addressed to Hua Qi, qhqihua@yahoo.com
}

Received 20 March 2012; Accepted 14 May 2012

Academic Editor: Renzhi Ma

Copyright () 2012 Hua Qi et al. This is an open access article distributed under the Creative Commons Attribution License, which permits unrestricted use, distribution, and reproduction in any medium, provided the original work is properly cited.

Vertically aligned, high-density $\mathrm{ZnO}$ nanowires (NWs) were grown for the first time on c-plane sapphire using binary alloys of $\mathrm{Ni} / \mathrm{Au}$ or $\mathrm{Cu} / \mathrm{Au}$ as the catalyst. The growth was performed under argon gas flow and involved the vapor-liquid-solid (VLS) growth process. We have investigated various ratios of catalyst components for the NWs growth and results indicate that very thin adhesion layers of $\mathrm{Ni}$ or $\mathrm{Cu}$ deposited prior to the Au layer are not deleterious to the $\mathrm{ZnO} \mathrm{NW}$ array growth. Significant improvement of the $\mathrm{Au}$ adhesion on the substrate was noted, opening the potential for direct catalyst patterning of Au and subsequent NW array growth. Additionally, we found that an increase of in thickness of the $\mathrm{Cu}$ adhesion layer results in the simultaneous growth of NWs and nanoplates (NPs), indicating that in this case the growth involves both the VLS and vapor-solid (VS) growth mechanisms. Energy dispersive X-ray spectroscopy (EDX) and surface-enhanced Raman scattering (SERS) studies were also performed to characterize the resulting $\mathrm{ZnO} \mathrm{NW}$ arrays, indicating that the NWs grown using a thin adhesion layer of $\mathrm{Ni}$ or $\mathrm{Cu} u n d e r$ the Au show comparable SERS enhancement to those of the pure Au-catalyzed NWs.

\section{Introduction}

One-dimensional zinc oxide $(\mathrm{ZnO})$ nanowires (NWs) have been attracting much attention because they can be used to design novel nanoscale devices due to their wide band gap, high mechanical stability, and high isoelectric point [1-13]. Recently, several growth techniques to produce vertically aligned $\mathrm{ZnO} \mathrm{NW}$ arrays have been studied, including the solution-based method [14] and vapor transport growth [15]. One of the well-established methods to grow nanowires is the vapor-liquid-solid (VLS) growth process, in which $\mathrm{Au}$ is used as the catalyst $[16,17]$. In the VLS process of $\mathrm{ZnO}$ growth, the $\mathrm{Au}$ islands on the substrate serve as the nucleation sites for the condensation of $\mathrm{Zn}$ vapor from a nearby $\mathrm{ZnO}$ source, and then the $\mathrm{ZnO}$ NWs grow from the supersaturated liquid eutectic $\mathrm{Zn}$-Au mixture.

Although vertical $\mathrm{ZnO}$ nanowire (NWs) arrays have been grown using pure $\mathrm{Au}$ catalyst [7], the use of these $\mathrm{ZnO}$ NW arrays in the design and fabrication of new plasmonic structures is limited due to the poor adhesion of $\mathrm{Au}$ on the required sapphire or $\mathrm{GaN}$ substrates, which is well known. Since there is very little information available on the metal catalyst adhesion issues for the growth of vertically aligned
ZnO NWs or the affects of using the bilayered metal catalysts for such growth, we have initiated such a study. Thus, we have investigated the use of adhesion layers of different metals, including $\mathrm{Cu}, \mathrm{Ni}, \mathrm{Cr}, \mathrm{Ti}$ and their bi-layers with $\mathrm{Au}$, in order to grow vertically aligned $\mathrm{ZnO} \mathrm{NWs}$ on c-sapphire, which would be amenable to nanopatterning and further device fabrication. In the standard single metal species catalyst VLS process, a simple binary eutectic is employed, but it becomes much more challenging in the case of bilayered metal catalysts, in which a ternary eutectic may be formed. In our study, the vertical $\mathrm{ZnO} \mathrm{NWs}$ were successfully grown via bilayered metal catalysts and further characterized by high-resolution SEM/TEM with energy dispersive X-ray spectroscopy (EDX) capability. Additional characterization techniques also showed that the NWs grown using certain thin adhesion layers did not change their optical or structural properties, a necessary condition for future plasmonic device designs and fabrication.

\section{Experimental Details}

The growth of the vertical $\mathrm{ZnO} \mathrm{NW}$ arrays was carried out in a horizontal quartz tube. A mixture of $\mathrm{ZnO}: \mathrm{C}$ 


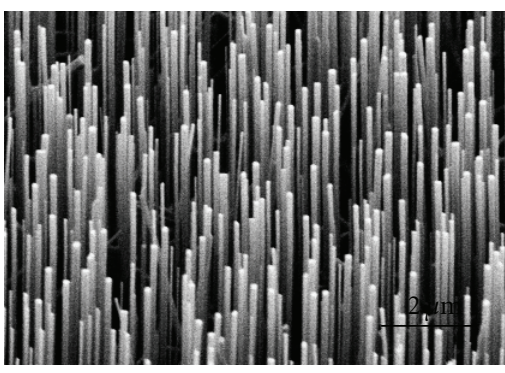

(a)

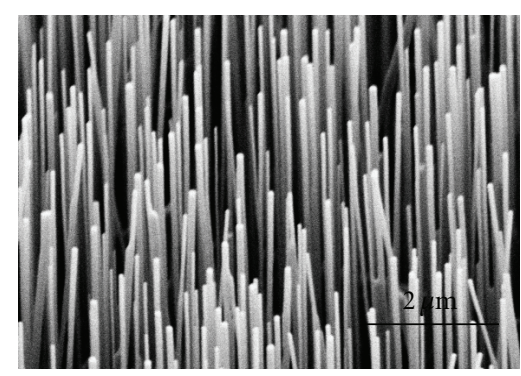

(b)

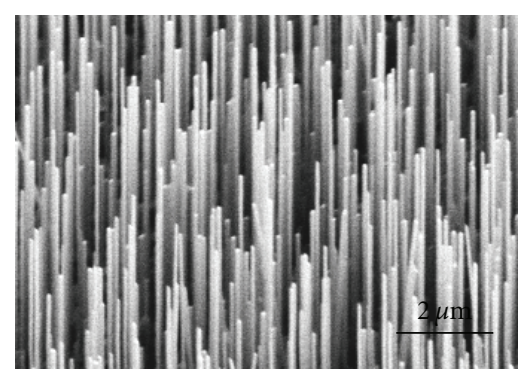

(c)

Figure 1: SEM images of vertical $\mathrm{ZnO}$ NWs grown using $1 \mathrm{~nm} \mathrm{Ni} / 5 \mathrm{~nm} \mathrm{Au}$ (a), $1 \mathrm{~nm} \mathrm{Cu} / 5 \mathrm{~nm} \mathrm{Au}$ (b), and $5 \mathrm{~nm}$ pure gold catalyst (c). Sample stage is tilted $45^{\circ}$ while imaging.

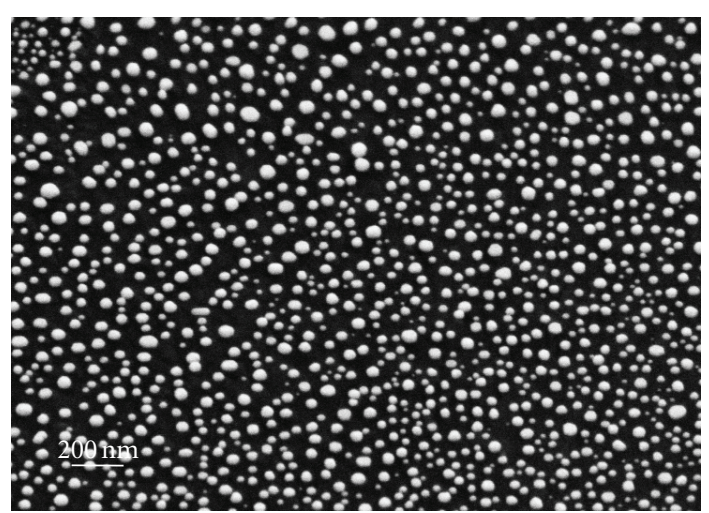

Figure 2: A representative SEM image of the particle sizes after the bi-layer metal thin films were deposited and annealed in a furnace, prior to the nanowires growth.

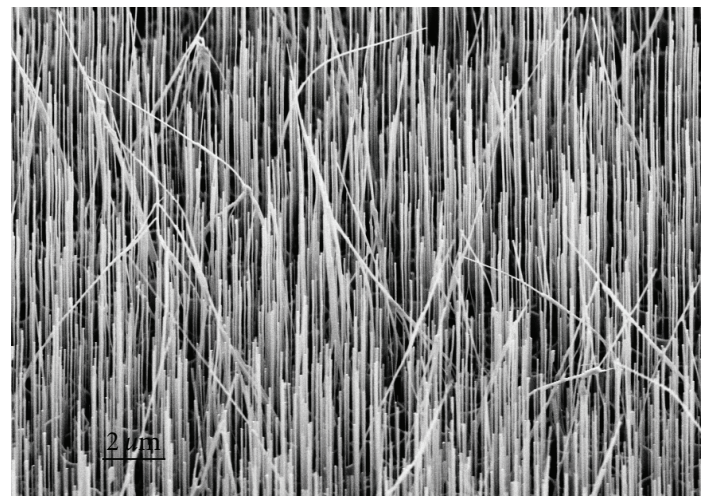

FIGURE 3: A typical SEM image of the nanowires growth with some extremely long nanowires.

( $1: 1$ by weight) source powder was placed in one end of an alumina boat, and the c-sapphire substrate with the metal catalyst thin films was placed above, facing the source. The furnace was heated to $900^{\circ} \mathrm{C}$ while argon flowed through the tube. Pure $\mathrm{Au}, \mathrm{Cu}, \mathrm{Ni}$, and alloys of $\mathrm{Cu}-\mathrm{Au}, \mathrm{Ni}-\mathrm{Au}, \mathrm{Cr}-$ $\mathrm{Au}$, and $\mathrm{Ti}-\mathrm{Au}$ were, respectively, deposited on separate csapphire substrates by an FC-2000 Temescal E-beam metals evaporation system, at an evaporation rate of $1 \AA / \mathrm{s}$, and used as the catalyst during the $\mathrm{ZnO}$ growth processes. The doublelayer alloys were deposited by a two-step process. Firstly the sapphire was covered with a layer of $\mathrm{Cu}$ or $\mathrm{Ni}$, which plays the important role of adhesion to the substrate. Secondly, the gold layer was deposited onto the $\mathrm{Cu}$ or Ni layer.

A LEO SUPRA 55 scanning electron microscope (SEM) with energy dispersive X-ray spectroscopy (EDX) capability was used to investigate the topographies and the chemical compositions of the NWs and the alloy tip formed during the growth process. The resulting NW samples that were used for the SERS analysis were as-grown samples, without any electron beam exposure in the SEM or EDX. For the lithography test process, a wraith 150 e-beam writer system and a standard procedure were employed to perform the e-beam lithography, and PMMA was used as the pattern writing resist.

For the surface-enhanced Raman spectroscopy (SERS) measurements, $8 \mathrm{~nm}$ of silver was deposited on the vertically aligned $\mathrm{ZnO} \mathrm{NWs}$ using an FC-2000 Temescal E-beam metals evaporation system, at an evaporation rate of $0.5 \AA / \mathrm{s}$. The samples were then immersed in a solution of benzenthiol $\left(10^{-3} \mathrm{M}\right)$ for $6 \mathrm{~h}$ and dried for SERS analysis. The SERS of the vertical NWs array samples was performed utilizing a Delta $\mathrm{Nu}$ system which consists of an Olympus Microscope and a Raman spectrometer equipped with a thermoelectrically cooled CCD. The $785 \mathrm{~nm}$ line of a Ti: Sapphire laser was used as the excitation source to detect the SERS. The microscope utilized a 50X $0.75 \mathrm{NA}$ objective for focusing the laser light. The spectra were collected with a laser power of $6 \mathrm{~mW}$ at the sample, and the laser spot size was about $2 \mu \mathrm{m}$.

\section{Results and Discussion}

The representative scanning electron microscope (SEM) images of bi-layers of $1 \mathrm{~nm} \mathrm{Ni} / 5 \mathrm{~nm} \mathrm{Au}, 1 \mathrm{~nm} \mathrm{Cu} / 5 \mathrm{~nm} \mathrm{Au}$, and pure $\mathrm{Au}$-catalyzed $\mathrm{ZnO} \mathrm{NWs}$ grown on c-sapphire are shown in Figures 1(a), 1(b), and 1(c), respectively. As can be seen, the successful growth of vertical $\mathrm{ZnO}$ using $\mathrm{Cu} / \mathrm{Au}$ and $\mathrm{Ni} / \mathrm{Au}$ bi-layers is clear, and these arrays exhibited the same morphology as the NWs grown by a pure gold catalyst (Figure 1(c)). The NWs display a highly vertical alignment on the c-sapphire substrate and an average diameter between $50-150 \mathrm{~nm}$, depending on the thickness of the catalyst [18]. 


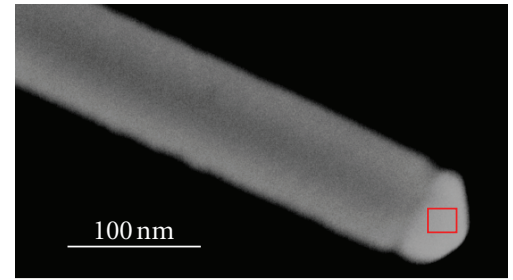

(a)

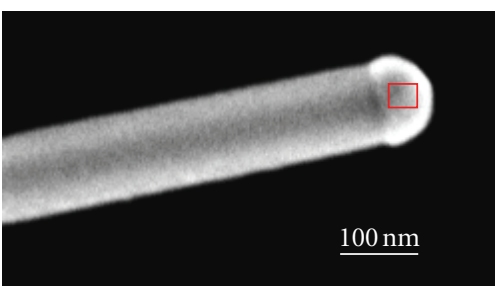

(b)

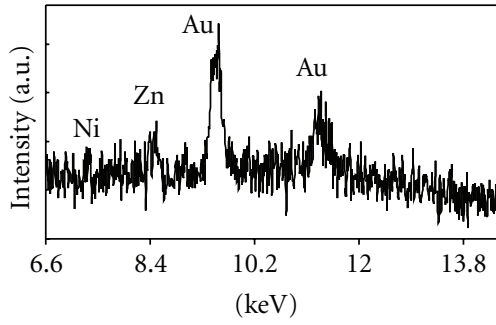

(c)

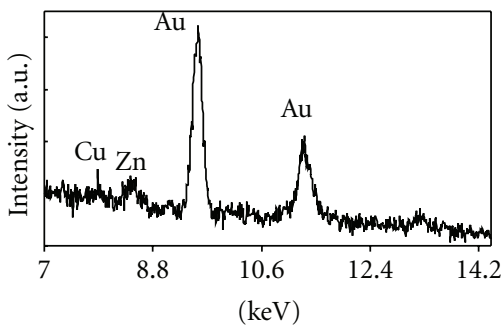

(d)

\begin{tabular}{ccccc}
\hline Element & $\mathrm{keV}$ & K ratio & $\mathrm{Wt} \%$ & $\mathrm{At} \%$ \\
\hline $\mathrm{Au}$ & 2.121 & 0.8884 & 93.83 & 83.11 \\
$\mathrm{Ni}$ & 7.477 & 0.0185 & 1.38 & 4.1 \\
$\mathrm{Zn}$ & 8.637 & 0.0658 & 4.79 & 12.79 \\
\hline Total & & & 100 & 100 \\
\hline
\end{tabular}

(e)

\begin{tabular}{ccccc}
\hline Element & $\mathrm{keV}$ & K ratio & $\mathrm{Wt} \%$ & $\mathrm{At} \%$ \\
\hline $\mathrm{Au}$ & 2.121 & 0.9482 & 97.33 & 92.29 \\
$\mathrm{Cu}$ & 8.046 & 0.0087 & 0.66 & 1.94 \\
$\mathrm{Zn}$ & 8.637 & 0.0283 & 2.02 & 5.77 \\
\hline Total & & & 100 & 100 \\
\hline
\end{tabular}

(f)

FIGURE 4: High-resolution SEM images of Ni/Au-catalyzed (a) and $\mathrm{Cu} / \mathrm{Au}$-catalyzed (b) ZnO single NW. EDX analysis patterns (c and d) of the alloy tip as shown in the red rectangle areas of (a) and (b). Composites analysis reports of tip alloy (e and f).

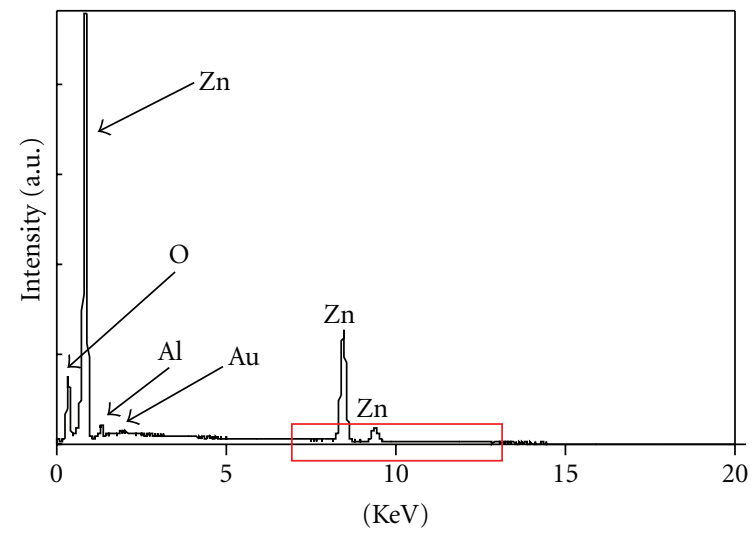

(a)

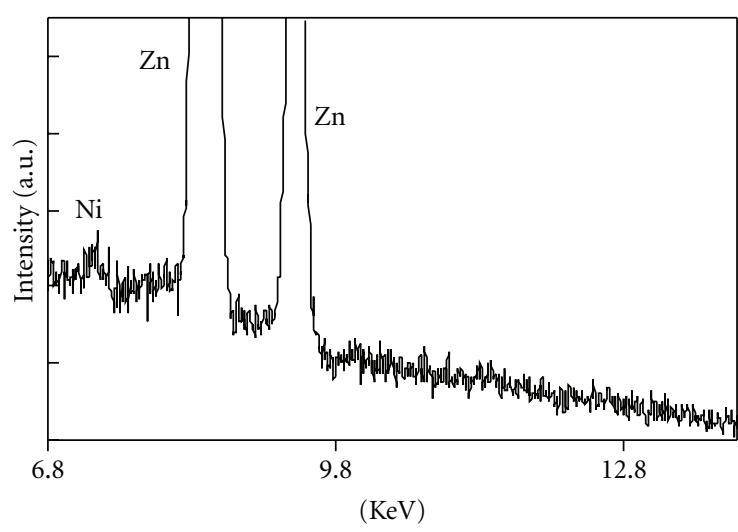

(b)

\begin{tabular}{cccccc}
\hline Element & $\mathrm{keV}$ & $\mathrm{K}$ Ratio & $\mathrm{Wt} \%$ & $\mathrm{At} \%$ & Chi-squared \\
\hline $\mathrm{Ni}$ & 7.477 & 0.0029 & 0.2 & 0.14 & 6.35 \\
$\mathrm{Au}$ & 2.121 & 0.0141 & 2.4 & 0.49 & 19.93 \\
$\mathrm{Zn}$ & 8.637 & 0.7173 & 76.71 & 47.27 & 6.35 \\
$\mathrm{O}$ & 0.523 & 0.1057 & 20.69 & 52.1 & 85.56 \\
\hline Total & & & 100 & 100 & 42.2 \\
\hline
\end{tabular}

(c)

FIGURE 5: Representative energy dispersive X-ray (EDX) spectroscopy of ZnO NWs grown on sapphire with catalysts of $1 \mathrm{~nm}$ Ni/5 nm Au alloy (a), a close-up plot (b) of the red rectangle region, and (c) a corresponding composition analysis of the large area of ZnO NWs.

Actually the catalyst particles are not fairly similar in size in the case where we deposited thin film bi-layers, which resulted in the random nanowires growth. We studied the particle sizes after the bi-layer metal thin films were deposited and annealed in a furnace, prior to the nanowires growth. A representative SEM image is shown in Figure 2, clearly demonstrating the inhomogeneity of the particles size, which leads to a huge size distribution in diameter. The particle sizes were much more uniform though if the bi-layer thin films were first patterned using e-beam lithography. However, our study was mostly concerned with adhesion as the first step before e-beam lithography, so most of our samples were grown using unpatterned bi-layer thin films as the catalysts. The lengths of these NWs can be varied from several hundreds of nanometers to longer than ten micrometers by adjusting the growth and gas flow time. In fact, there is 


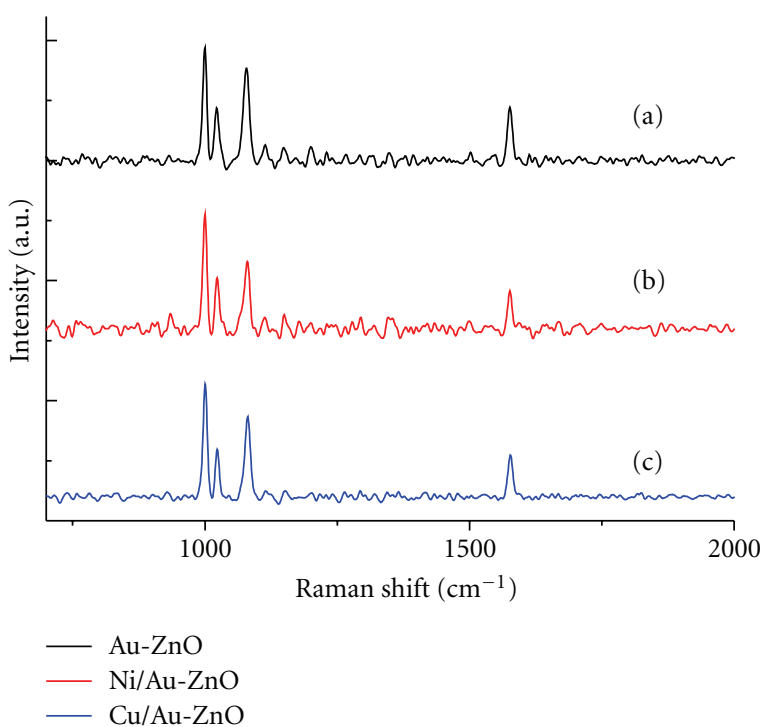

FIGURE 6: Surface-enhanced Raman spectroscopy (SERS) of vertical $\mathrm{ZnO} \mathrm{NWs}$ grown using (a) pure gold, (b) Ni/Au alloy, and (c) $\mathrm{Cu} / \mathrm{Au}$ alloy.

some relation between alignments with the length of the nanowire. If the nanowires grow extremely long (longer than 20 micrometers), the top of the nanowires begins to bend and cannot keep the vertical alignment, as shown in Figure 3. We have also found that the growth condition for the aligned $\mathrm{ZnO} \mathrm{NW}$ arrays has to be optimized by balancing the amount of all vapor phases in the system. In addition, the oxygen content in the system also plays an important role during the growth process [19]. Since, in our case, the base vacuum of the system was around 50 mTorr, which provided sufficient oxygen partial pressure, only argon gas was introduced to the system at a rate of $45 \mathrm{~mL} / \mathrm{min}$ during the whole growth process.

The NWs as grown on sapphire were further analyzed by energy dispersive X-ray spectroscopy (EDX) to confirm the successful growth and stoichiometry of the $\mathrm{ZnO}$ NWs. The EDX signal intensities are comparable to the $\mathrm{Zn}$ signal strength obtained from the NWs grown via pure $\mathrm{Au}$, demonstrating the high density of NWs in these cases. To investigate the detailed information of the grown NWs with $\mathrm{Ni} / \mathrm{Au}$ or $\mathrm{Cu} / \mathrm{Au}$ bilayered catalysts, we performed highresolution SEM and EDX investigations on a single NW and its alloy tip. As shown in Figures 4(a) and 4(b), the metal alloy tip was clearly observed at the end of NW, indicating that the $\mathrm{ZnO} \mathrm{NW}$ growth involves the vapor-liquid-solid (VLS) mechanism. Further EDX analyses of these metal tips (the red rectangle area shown in Figures 4(a) and 4(b)) at high magnification demonstrate that the tips are indeed ternary composites of $\mathrm{Cu} / \mathrm{Au} / \mathrm{Zn}$ or Ni/Au/Zn and are not simpley an Au-Zn binary. As shown in Figures 4(c), 4(d), 4(e), and 4(f), the EDX pattern and the data analysis clearly indicate the presence of the ternary alloy during the $\mathrm{ZnO}$ NWs VLS growth process. In addition, the surface of the NW is smooth and no segregation was observed, which is in good agreement with our expectation based on $\mathrm{Cu} / \mathrm{Au}$ or $\mathrm{Ni} / \mathrm{Au}$ phase diagrams. Specifically in the case of the $\mathrm{Cu} / \mathrm{Au}$ or $\mathrm{Ni} / \mathrm{Au}$ system, the phase diagrams indicate a continuous solid solution exists at the temperatures of interest in our work, so no segregation was expected. Although the phase diagram of $\mathrm{Cu} / \mathrm{Au}$ also indicates a series of solid state transformations at much lower temperatures, the data indicate that they are only stable at a very narrow temperature window significantly below our growth temperature.

It is noted that less amount of $\mathrm{Ni}$ is observed in the tip than those initial catalyst composites as deposited. We attributed this observation to the loss of $\mathrm{Ni}$ by diffusion into the growing $\mathrm{ZnO} \mathrm{NW}$, since kinetics also plays an important role and it is well established that $\mathrm{Ni}$ is a fast diffuser in many systems. This supposition is further confirmed by using SEM/EDX to scan a large area of NWs. Figures 5(a) and 5(b) show the representative EDX curves obtained on a large area of $\mathrm{ZnO} N W$ s grown by $1 \mathrm{~nm} \mathrm{Ni} / 5 \mathrm{~nm}$ Au catalysts and a close-up plot of $\mathrm{Ni}$ element region. A Ni signal can be recognized clearly, and NWs composites analysis was shown in Figure 5(c), demonstrating that the ratio of $\mathrm{Ni}$ to $\mathrm{Au}$ is 0.14 to 0.49 . This value is very close to the original layer composites produced by e-beam deposition, clearly indicating the diffusion of $\mathrm{Ni}$ during the $\mathrm{ZnO} \mathrm{NW}$ growth process.

Figure 6 shows representative surface-enhanced Raman spectroscopy (SERS) spectra of benzenthiol measured on the NWs grown using $\mathrm{Au}, \mathrm{Cu} / \mathrm{Au}$, and $\mathrm{Ni} / \mathrm{Au}$ bi-layer catalysts, respectively. The major Raman peaks at 1000, 1023, 1081, and $1576 \mathrm{~cm}^{-1}$ can be assigned to symmetric ring breathing, in-plane $\mathrm{C}-\mathrm{H}$ bending, wagging of the $\mathrm{CH}_{2}$ groups, and in-plane $\mathrm{C}-\mathrm{C}$ stretching modes, respectively, of the phenyl ring from benzenthiol [20-23]. As can be seen, the $\mathrm{Cu} / \mathrm{Au}$ or Ni/Au bi-layer catalyzed NWs result in a comparable SERS enhancement factor as that of the pure Au-catalyzed NWs, indicating that the plasmon properties of the bilayered metal-catalyzed $\mathrm{ZnO} \mathrm{NW}$ arrays are not affected. In order to produce arrays with $50 \mathrm{~nm}$ diameters and with wire-to-wire spacing on the order of $10-50 \mathrm{~nm}$ for plasmonic applications, e-beam lithography is necessary, in which the use of an adhesion layer is critical. In addition, this study also provides a useful way for any other nanodevice fabrications based on the patterned $\mathrm{ZnO}$ NWs arrays. More characterization indicated that the optical proeperties as revealed by roomtemperature photoluminescence (PL) property of these $\mathrm{Ni} / \mathrm{Au}$ or $\mathrm{Cu} / \mathrm{Au}$ bi-layer catalyzed NWs are comparable to those of the Au-catalyzed NWs, further demonstrating the feasibility of growing high-quality NWs via these bilayered film catalysts.

Additionally, the NWs can still grow with increasing $\mathrm{Cu}$ or $\mathrm{Ni}$ ratio in the $\mathrm{Cu}-\mathrm{Au}$ and $\mathrm{Ni}-\mathrm{Au}$ layers as shown in Figure 7, including the growths using catalysts (a) $3 \mathrm{~nm}$ $\mathrm{Cu} / 3 \mathrm{~nm} \mathrm{Au}$, (b) $5 \mathrm{~nm} \mathrm{Cu} / 1 \mathrm{~nm} \mathrm{Au}$, (c) pure $5 \mathrm{~nm} \mathrm{Cu}$, (d) $3 \mathrm{~nm} \mathrm{Ni} / 3 \mathrm{~nm} \mathrm{Au}$, (e) $1 \mathrm{~nm} \mathrm{Ti} / 5 \mathrm{~nm} \mathrm{Au}$, and (f) $1 \mathrm{~nm}$ $\mathrm{Cr} / 5 \mathrm{~nm} \mathrm{Au}$. However, the growths exhibit a mixed morphology of NWs and nanoplates (NPs), most likely a result of varying the metal content of the nucleated catalyst islands. Figure 7(b) is a typical image with clear NWs and NPs obtained on the growth using $5 \mathrm{~nm} \mathrm{Cu} / 1 \mathrm{~nm}$ Au catalysts. Although the NWs grow by the vapor-liquid-solid (VLS) 


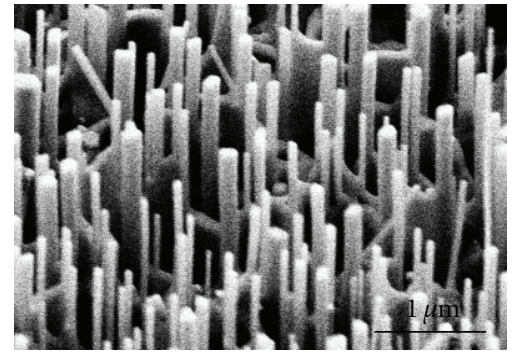

(a)

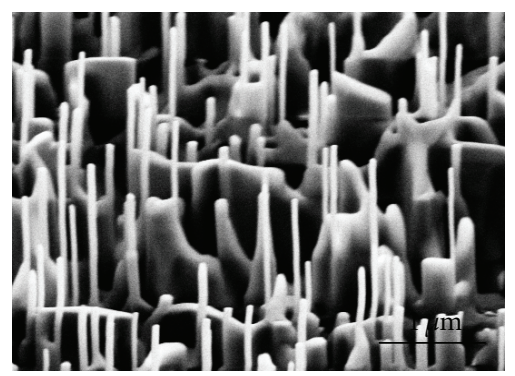

(d)

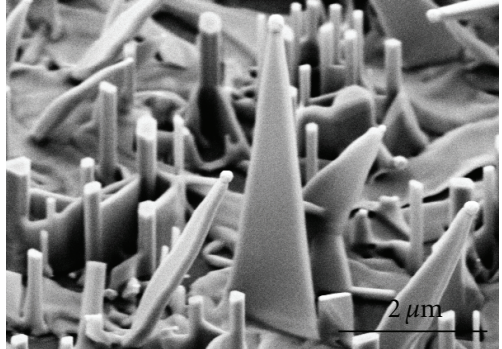

(b)

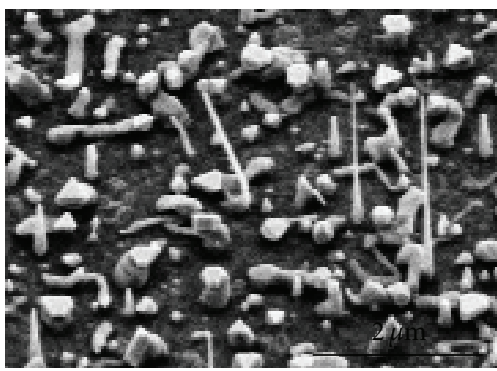

(e)

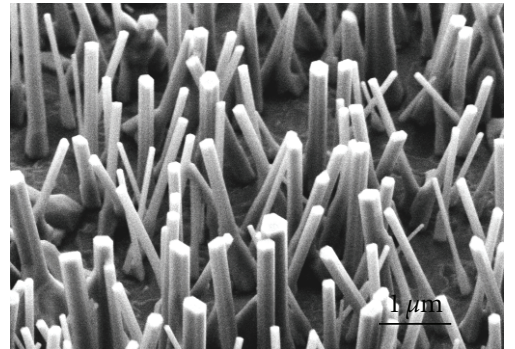

(c)

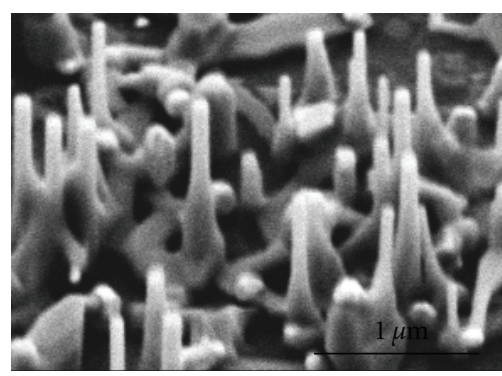

(f)

Figure 7: SEM images of $\mathrm{ZnO}$ nanostructures growth with different alloy or pure metal catalysts on sapphire. $(\mathrm{a}) \mathrm{Cu} / \mathrm{Au}=3 \mathrm{~nm} / 3 \mathrm{~nm}$; $(\mathrm{b})$ $\mathrm{Cu} / \mathrm{Au}=5 \mathrm{~nm} / 1 \mathrm{~nm}$; (c) pure $\mathrm{Cu}=5 \mathrm{~nm} ;(\mathrm{d}) \mathrm{Ni} / \mathrm{Au}=3 \mathrm{~nm} / 3 \mathrm{~nm}$; (e) Ti/Au $=1 \mathrm{~nm} / 5 \mathrm{~nm}$; (f) $\mathrm{Cr} / \mathrm{Au}=1 \mathrm{~nm} / 5 \mathrm{~nm}$.

mechanism, the NPs most likely grow by a combination of VLS-VS (vapor-solid) mechanism, which has been reported by Dong et al. and Dai et al. [24, 25], in the CdSe and CdS system. In our case, during the early stage of the growth, $\mathrm{ZnO}$ NWs grew from the liquid supersaturated eutectic $\mathrm{Zn} / \mathrm{Au} / \mathrm{Cu}$ mixture by the VLS mechanism. In the process of the $\mathrm{ZnO}$ growth, the metal alloy remains at the tip of the NW, which is clearly shown in the SEM images. At the same time, excess $\mathrm{Zn}$ vapor is deposited on the sidewalls of some of the alreadygrown NWs, resulting in the NPs growth, involving both VLS and VS growth modes. Moreover, pure $\mathrm{Ni}, \mathrm{Cu}, \mathrm{Ti} / \mathrm{Au}$, and $\mathrm{Cr} / \mathrm{Au}$ layers were also investigated. Sparse vertical $\mathrm{ZnO}$ NWs were obtained using $\mathrm{Cr} 1 \mathrm{~nm} / \mathrm{Au} 5 \mathrm{~nm}$ as the bi-layer catalyst, whereas very few NWs grew using Ti $1 \mathrm{~nm} / \mathrm{Au} 5 \mathrm{~nm}$. Table 1 presents the detailed information of pure metal or metal layers component catalysts, the morphology of the growth, the length, and the diameters of the resulting $\mathrm{ZnO}$ nanostructures as grown.

It should be pointed out that, in the case of the bilayered metal catalysts, we are dealing with a three-component system, which is a much more complicated thermodynamic case than the standard two-component system. In the case of the two-component system, it is fairly easy to obtain a phase diagram for the two constituents and from that determine the potential for the formation of a eutectic, as well as the expected eutectic temperature. In our case, however, we are dealing with a metal $(\mathrm{Cu}, \mathrm{Ni}, \mathrm{Ti}$, or $\mathrm{Cr})-\mathrm{Au}-\mathrm{Zn}$ that will form ternary phases. Unfortunately, these ternary phase diagrams for temperatures of interest are not available in the literature. Thus, it is impossible to obtain the eutectic point or temperature information from a phase diagram, and thus it is necessary to provide experimental data for the viability of the growth process of these NWs.
It is well known that the Scotch tape is commonly used to investigate the adhesion of metal film on a substrate [26-28]. In our study, the very thin layer of $1 \mathrm{~nm} \mathrm{Cu}$ or $1 \mathrm{~nm} \mathrm{Ni}$ deposited prior to the Au layer passed this Scotch tape test successfully, without causing any metal detachment, while a pure gold layer partially peeled off, confirming the need for the use of a bilayered metal.

The improvement of adhesive capability of gold on sapphire was further confirmed by e-beam lithography experiments, which are shown in Figure 8. It is clear that part of the metal layer delaminated when pure gold was used as a lift-off metal in acetone after e-beam pattern writing. In fact, the e-beam pattern lithography results in the loss of the designed pattern completely as shown in Figure 8(a). However we successfully obtained a designed pattern when a thin layer of $1 \mathrm{~nm} \mathrm{Ni}$ was introduced under gold (Figure $8(\mathrm{~b})$ ), which clearly demonstrates the enhancement of the metal adhesion. It is well known that the formation of a Ni-O bond is much easier than that of an $\mathrm{Au}-\mathrm{O}$ bond, which can enhance the adhesion of $\mathrm{Ni}$ on a substrate [29]. Indeed $\mathrm{Au}$ is an inert metal in the air, and this property obviously decreases its stickiness to the substrate. Furthermore, it has been well established by the semiconductor device community that the adhesion of $\mathrm{Au}$ can be significantly improved by the addition of a $\mathrm{Ni}$ or $\mathrm{Cr}$ layer.

\section{Conclusion}

High-quality vertically aligned $\mathrm{ZnO} \mathrm{NW}$ arrays were grown for the first time using bilayered metal catalysts of $\mathrm{Ni} / \mathrm{Au}$ and $\mathrm{Cu} / \mathrm{Au}$, respectively. We show that their structural and 
TABLE 1: Experimental growth conditions and results of ZnO NW samples.

\begin{tabular}{lclcc}
\hline Samples & Thickness of metal $(\mathrm{nm})$ & Morphology & NW length & NW diameter $(\mathrm{nm})$ \\
\hline $\mathrm{A}$ & $\mathrm{Cu}: \mathrm{Au}=1 \mathrm{~nm}: 5 \mathrm{~nm}$ & Vertically aligned NW & $>5 \mu \mathrm{m}$ & $20-200$ \\
$\mathrm{~B}$ & $\mathrm{Cu}: \mathrm{Au}=3 \mathrm{~nm}: 3 \mathrm{~nm}$ & Vertical NW & $>2 \mu \mathrm{m}$ & $20-200$ \\
$\mathrm{C}$ & $\mathrm{Cu}: \mathrm{Au}=5 \mathrm{~nm}: 1 \mathrm{~nm}$ & Mixture growth of vertical NW and nano-wall & $<2 \mu \mathrm{m}$ & $>5 \mu \mathrm{m}$ \\
$\mathrm{D}$ & $\mathrm{Ni}: \mathrm{Au}=1 \mathrm{~nm}: 5 \mathrm{~nm}$ & Vertically aligned NW & $500 \mathrm{~nm}-2 \mu \mathrm{m}$ & $20-200$ \\
$\mathrm{E}$ & $\mathrm{Ni}: \mathrm{Au}=3 \mathrm{~nm}: 3 \mathrm{~nm}$ & Vertically NW and nano-wall & $>2 \mu \mathrm{m}$ & $50-300$ \\
$\mathrm{~F}$ & $\mathrm{Cu}=5 \mathrm{~nm}$ & Mostly vertical NW & $<200 \mathrm{~nm}$ & $50-300$ \\
$\mathrm{G}$ & $\mathrm{Ni}=5 \mathrm{~nm}$ & Few sparse and short NW & $<3 \mu \mathrm{m}$ & $30-60$ \\
$\mathrm{H}$ & $\mathrm{Ti}: \mathrm{Au}=1 \mathrm{~nm}: 5 \mathrm{~nm}$ & Few vertical NW & $400 \mathrm{~nm}-2 \mu \mathrm{m}$ & $60-150$ \\
$\mathrm{I}$ & $\mathrm{Cr}: \mathrm{Au}=1 \mathrm{~nm}: 5 \mathrm{~nm}$ & Sparse and vertical NW & $>5 \mu \mathrm{m}$ & $60-200$ \\
$\mathrm{~J}$ & $\mathrm{Au}=5 \mathrm{~nm}$ & Vertically aligned NW & & $20-200$ \\
\hline
\end{tabular}

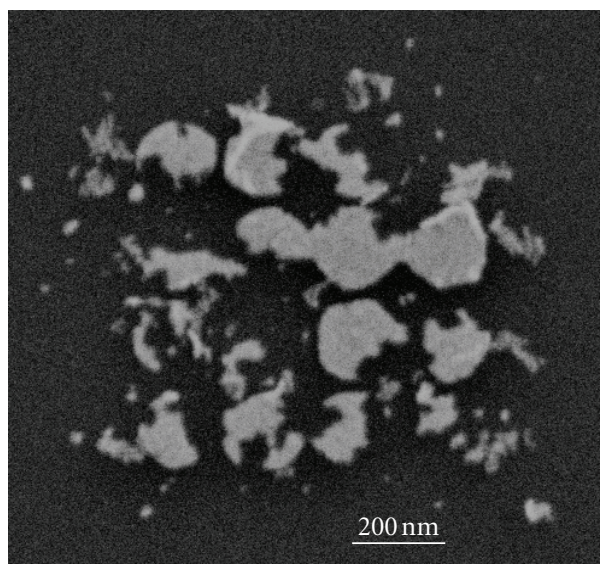

(a)

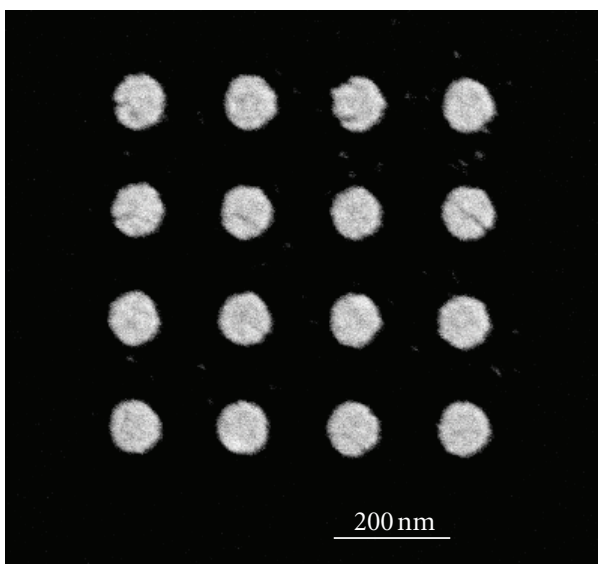

(b)

Figure 8: E-beam lithography and following lift-off results with (a) pure gold and (b) Ni/Au $=1 \mathrm{~nm} / 5 \mathrm{~nm}$ alloy.

optical properties are comparable to those of pure $\mathrm{Au}$ catalyzed NWs. An advantage in this case is that Ni/Au or $\mathrm{Cu} / \mathrm{Au}$ bi-layers display better adhesion properties than a pure gold catalyst, enabling potential patterning of these $\mathrm{ZnO}$ nanowire arrays prior to growth, which is critical for potential plasmonic applications. Due to the VLS growth process, we can also demonstrate high selectivity of the vertical $\mathrm{ZnO} \mathrm{NW}$ array growth, which occurs only in the patterned catalyst region. This work can have a significant impact on the ability to form very tightly spaced ordered nanowire arrays for plasmonic applications, which are not possible currently due to the adhesion problems of the Au dots formed by e-beam lithography, providing a direct route for the growth of vertically aligned $\mathrm{ZnO}$ NWs in any desired pattern for novel nanoscale plasmonic structures.

\section{Acknowledgments}

This work was supported by the Office of Naval Research (ONR) and Nanoscience Institute (NSI) of the US Naval Research Laboratory.

\section{References}

[1] X. D. Wang, J. Liu, Z. L. Wang, and J. Song, "Direct-current nanogenerator driven by ultrasonic waves," Science, vol. 316, no. 5821, pp. 102-105, 2007.

[2] Z. L. Wang and J. Song, "Piezoelectric nanogenerators based on zinc oxide nanowire arrays," Science, vol. 312, no. 5771, pp. 242-246, 2006.

[3] C. H. Chen, S. J. Chang, S. P. Chang et al., "Novel fabrication of UV photodetector based on $\mathrm{ZnO}$ nanowire/p-GaN heterojunction," Chemical Physics Letters, vol. 476, no. 1-3, pp. 6972, 2009.

[4] C. C. Lin, W. H. Lin, and Y. Y. Li, "Synthesis of $\mathrm{ZnO}$ nanowires and their applications as an ultraviolet photodetector," Journal of Nanoscience and Nanotechnology, vol. 9, no. 5, pp. 28132819, 2009.

[5] B. Weintraub, S. Chang, S. Singamaneni et al., "Densitycontrolled, solution-based growth of $\mathrm{ZnO}$ nanorod arrays via layer-by-layer polymer thin films for enhanced field emission," Nanotechnology, vol. 19, no. 43, Article ID 435302, 2008.

[6] C. Y. Lee, T. Y. Tseng, S. Y. Li, and P. Lin, "Electrical characterizations of a controllable field emission triode based on low temperature synthesized $\mathrm{ZnO}$ nanowires," Nanotechnology, vol. 17, no. 1, pp. 83-88, 2006. 
[7] M. H. Huang, S. Mao, H. Feick et al., "Room-temperature ultraviolet nanowire nanolasers," Science, vol. 292, no. 5523, pp. 1897-1899, 2001.

[8] K. Black, A. C. Jones, I. Alexandrou, P. N. Heys, and P. R. Chalker, "The optical properties of vertically aligned $\mathrm{ZnO}$ nanowires deposited using a dimethylzinc adduct," Nanotechnology, vol. 21, no. 4, Article ID 045701, 2010.

[9] K. S. Leschkies, R. Divakar, J. Basu et al., "Photosensitization of $\mathrm{ZnO}$ nanowires with CdSe quantum dots for photovoltaic devices," Nano Letters, vol. 7, no. 6, pp. 1793-1798, 2007.

[10] Y. Tak, S. J. Hong, J. S. Lee, and K. Yong, "Fabrication of $\mathrm{ZnO} / \mathrm{CdS}$ core/shell nanowire arrays for efficient solar energy conversion," Journal of Materials Chemistry, vol. 19, no. 33, pp. 5945-5951, 2009.

[11] V. Pachauri, A. Vlandas, K. Kern, and K. Balasubramanian, "Site-specific self-assembled liquid-gated $\mathrm{ZnO}$ nanowire transistors for sensing applications," Small, vol. 6, no. 4, pp. 589594, 2010.

[12] J. P. Liu, C. X. Guo, C. M. Li et al., "Carbon-decorated ZnO nanowire array: a novel platform for direct electrochemistry of enzymes and biosensing applications," Electrochemistry Communications, vol. 11, no. 1, pp. 202-205, 2009.

[13] X Zhang, A. Hu, T. Zhang, X. Xue, J. Wen, and W. W. Duley, "Subwavelength plasmonic waveguides based on $\mathrm{ZnO}$ nanowires and nanotubes: a theoretical study of thermooptical properties," Applied Physics Letters, vol. 96, no. 4, Article ID 043109, 2010.

[14] L. E. Greene, B. D. Yuhas, M. Law, D. Zitoun, and P. D. Yang, "Solution-grown zinc oxide nanowires," Inorganic Chemistry, vol. 45, no. 19, pp. 7535-7543, 2006.

[15] S. M. Prokes, O. J. Glembocki, R. W. Rendell, and M. G. Ancona, "Enhanced plasmon coupling in crossed dielectric/metal nanowire composite geometries and applications to surface-enhanced Raman spectroscopy," Applied Physics Letters, vol. 90, no. 9, Article ID 093105, 2007.

[16] S. Shafiei, A. Nourbakhsh, B. Ganjipour, M. Zahedifar, and G. Vakili-Nezhaad, "Diameter optimization of VLS-synthesized $\mathrm{ZnO}$ nanowires, using statistical design of experiment," Nanotechnology, vol. 18, no. 35, Article ID 355708, 2007.

[17] H. Qi, O. J. Glembocki, and S. M. Prokes, "Plasmonic properties of vertically aligned nanowire arrays," Journal of Nanomaterials, vol. 2012, Article ID 843402, 7 pages, 2012.

[18] Q. X. Zhao, P. Klason, and M. Willander, "Growth of $\mathrm{ZnO}$ nanostructures by vapor-liquid-solid method," Applied Physics A, vol. 88, no. 1, pp. 27-30, 2007.

[19] K. Subannajui, N. Ramgir, R. Grimm et al., " $\mathrm{ZnO}$ nanowire growth: a deeper understanding based on simulations and controlled oxygen experiments," Crystal Growth \& Design, vol. 10, no. 4, pp. 1585-1589, 2010.

[20] H. Qi, D. Alexson, O. Glembocki, and S. M. Prokes, "Plasmonic coupling on dielectric nanowire core-metal sheath composites," Nanotechnology, vol. 21, no. 8, Article ID 085705, 2010.

[21] R. Aroca and A. Thedchanamoorthy, "Vibrational studies of molecular organization in evaporated phthalocyanine thin solid films," Chemistry of Materials, vol. 7, no. 1, pp. 69-74, 1995.

[22] M. Lütt, M. R. Fitzsimmons, and D. Q. Li, "X-ray reflectivity study of self-assembled thin films of macrocycles and macromolecules," The Journal of Physical Chemistry B, vol. 102, no. 2, pp. 400-405, 1998.
[23] H. Qi, D. Alexson, O. Glembocki, and S. M. Prokes, "The effect of size and size distribution on the oxidation kinetics and plasmonics of nanoscale Ag particles," Nanotechnology, vol. 21, no. 21, Article ID 215706, 2010.

[24] L. F. Dong, J. Jiao, M. Coulter, and L. Love, "Catalytic growth of CdS nanobelts and nanowires on tungsten substrates," Chemical Physics Letters, vol. 376, no. 5-6, pp. 653-658, 2003.

[25] G. Z. Dai, Q. L. Zhang, Z. W. Peng et al., "One-step synthesis of low-dimensional CdSe nanostructures and optical waveguide of CdSe nanowires," Journal of Physics D, vol. 41, no. 13, Article ID 135301, 2008.

[26] L. A. Baker, F. P. Zamborini, L. Sun, and R. M. Crooks, "Dendrimer-mediated adhesion between vapor-deposited Au and glass or Si wafers," Analytical Chemistry, vol. 71, no. 19, pp. 4403-4406, 1999.

[27] M. Charbonnier, Y. Goepfert, M. Romand, and D. Leonard, "Electroless plating of glass and silicon substrates through surface pretreatments involving plasma-polymerization and grafting processes," The Journal of Adhesion, vol. 80, no. 12, pp. 1103-1130, 2004.

[28] M. Charbonnier, M. Romand, Y. Goepfert, D. Léonard, and M. Bouadi, "Copper metallization of polymers by a palladiumfree electroless process," Surface and Coatings Technology, vol. 200, no. 18-19, pp. 5478-5486, 2006.

[29] S. E. Kulkova, S. V. Eremeev, S. Hocker, and S. Schmauder, "Electronic structure and adhesion on metal-aluminum-oxide interfaces," Physics of the Solid State, vol. 52, no. 12, pp. 25892595, 2010. 

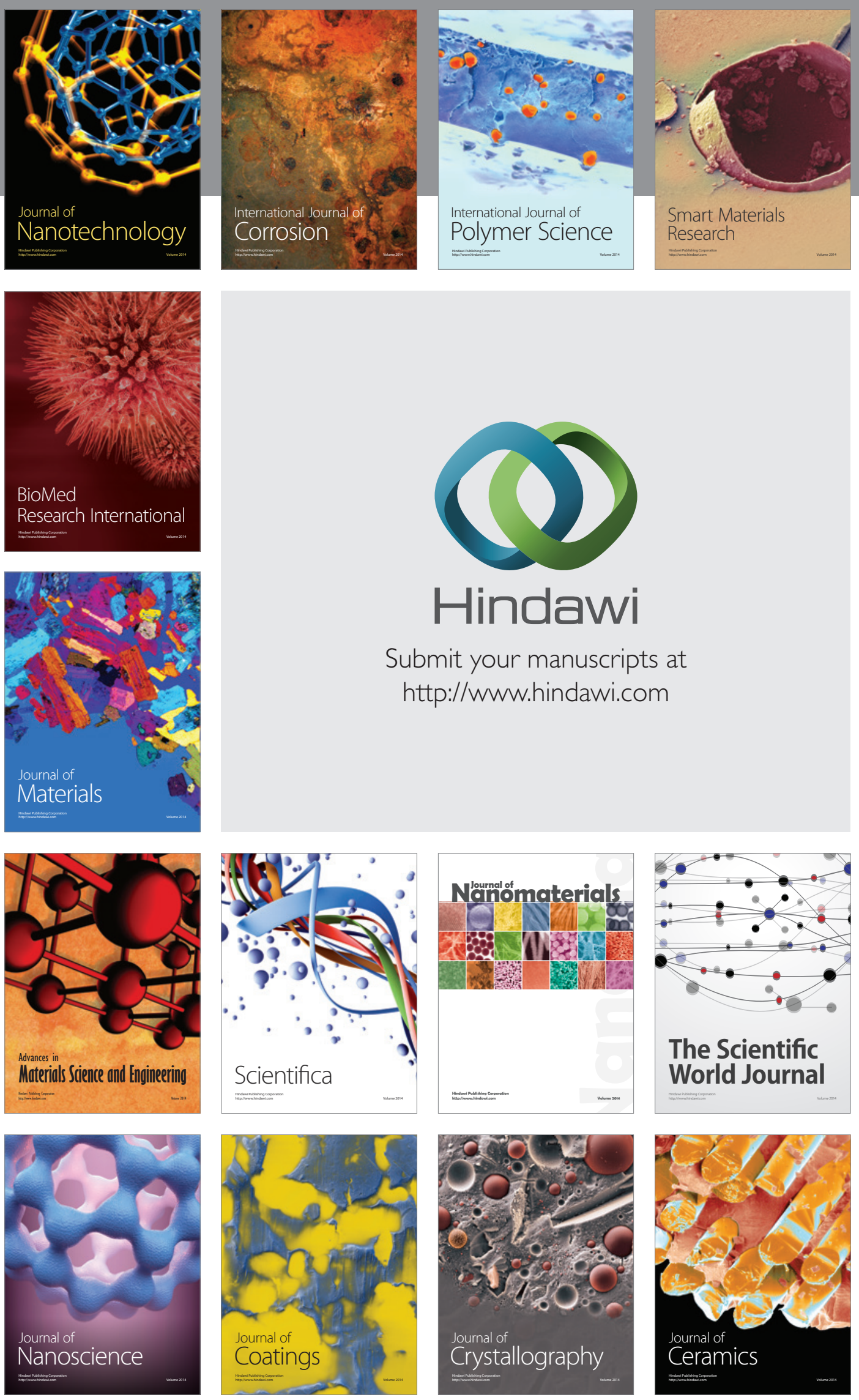

The Scientific World Journal

Submit your manuscripts at

http://www.hindawi.com

\section{World Journal}

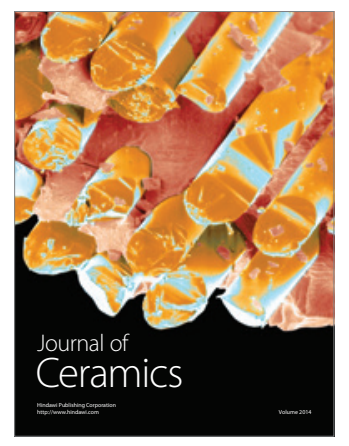

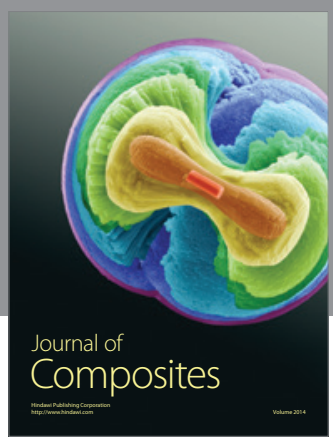
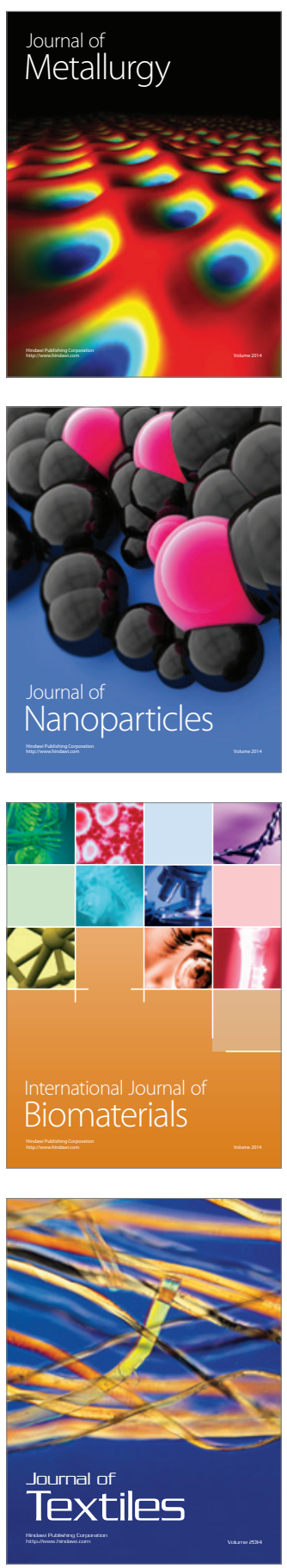